\title{
The classroom comes alive: Team-based active learning in an undergraduate psychiatric mental health nursing course
}

\author{
Joy Ann Lauerer *'Berry Anderson, Teresa Atz , Kimbi Marenakos \\ Medical University of South Carolina, Charleston, United States
}

Received: April 12, 2017

DOI: $10.5430 /$ jnep.v7n11p107

\author{
Accepted: May 15, 2017 \\ Online Published: July 3, 2017 \\ URL: https://doi.org/10.5430/jnep.v7n11p107
}

\begin{abstract}
Many undergraduate students enter psychiatric mental health nursing with anxiety, fear, and negative attitudes related to the patient population and their complex care. This issue is further complicated by the unique learning needs of an increasingly diverse group of students who require innovative, multi-modal teaching strategies. Faculty strive to provide active learning strategies to help students practice mental health nursing skills within a safe and non-threatening environment. These educational interventions can further develop self-confidence in student nurses to provide safe and therapeutic nursing care. This article discusses integrating components of flipped classroom and active, team-based learning into an undergraduate psychiatric mental health-nursing course.
\end{abstract}

Key Words: Education, Active learning, Innovation, Student focused, Content expert

\section{INTRODUCTION}

Communication skills and establishing therapeutic nursepatient relationships are the foundation of psychiatric mental health nursing. ${ }^{[1]}$ Comfort and confidence with these skills are often lacking in nursing students. Historically, psychiatric mental health nursing in undergraduate programs has been a source of fear, anxiety and stress for many students. ${ }^{[2]}$ Students sometimes fear the patients' unpredictable behaviors and situations they may encounter in the clinical setting. ${ }^{[3]}$ Previous studies have shown that anxiety, fear and negative attitudes are barriers to cultivating an effective therapeutic relationship. ${ }^{[1]}$ In addition, students' preconceived ideas and stigma about mentally ill patients they will encounter are at times negative, which increases stress and anxiety, and decreases self-confidence and the ability to provide for the complex needs of these patients. ${ }^{[1]}$ Also, with competition for clinical placements, faculty is charged to provide students with the opportunity to learn and practice mental health nursing skills in alternative locations, such as the classroom.

The Institute of Medicine (IOM) and the Carnegie report on nursing education, calls on nursing educators to develop and implement innovative and creative education strategies that meet diverse student needs, provide positive impacts on nursing student outcomes, and enable knowledge transfer from the classroom to clinical practice. ${ }^{[4,5]}$ More specifically, the IOM asks faculty to focus on the current health care issues of chronic illness such as diabetes, heart disease and mental health conditions. The American Association of Colleges of Nursing includes strong critical reasoning, clinical judgment, communication, and assessment skills as essentials for

*Correspondence: Joy Ann Lauerer; Email: lauerer@musc.edu; Address: Medical University of South Carolina, Charleston, United States. 
baccalaureate nursing education. ${ }^{[6]}$ These essential skills are major foci of nursing education to enhance patient-centered care, and promote safety, satisfaction and positive patient outcomes. Psychiatric mental health nursing faculty often struggle to meet these recommendations in complex learning environments with diverse student populations.

\section{Active learning}

Bergmann and Sams define flipped learning as a pedagogical approach that moves classroom learning into a more individual space, encouraging students to take more responsibility for the learning process. The flipped classroom encourages faculty to move away from traditional lecturing and invites students to immerse themselves in the content prior to attending class. ${ }^{[7]}$ Harmon and Hills described this shift as students moving from passive learners to active participants in their acquisition of knowledge. ${ }^{[8]}$ The classroom becomes the place to work through clinical problems, advance concepts, and engage in interactive learning. Immersion in the course content is assigned creatively and encourages students to come into the classroom and engage in collaborative learning. This dynamic environment entices the students to participate, share and formulate ideas and questions that encourage enhanced critical thinking skills. ${ }^{[9]}$

Team-based learning (TBL) is a form of active learning that works particularly well with large classes, up to 200 students to one instructor. ${ }^{[10]}$ The faculty member serves as a coach or a guide instead of the "expert," and encourages the students to assume more of the responsibility for learning. Within their assigned groups, the students also serve as models, mentors, and guides for each other, giving and receiving increasing support. As the group becomes more cohesive as each member develops a sense of belonging. ${ }^{[8]}$ Examples of team-based classroom learning activities include problem-based case studies, role-play and student prepared and facilitated competitive educational games. These activities promote problem solving, critical thinking, clinical application, and interpersonal communication skills. ${ }^{[10]}$ When the flipped classroom is combined with an active teambased learning model, students use class time to problem solve, discuss and expound upon content, collaborate, and apply concepts in a dynamic environment. Faculty in a major Southeast public nursing college developed and implemented an innovative teaching initiative to meet the challenges and recommendations of educating undergraduate baccalaureate nursing students in a psychiatric mental health nursing course. The purpose of this initiative was to improve student engagement, satisfaction, examination grades, and nationally normed, standardized exam pass rates in a psychiatric mental health course with team-based peer coaching activities.

\section{EDUCATIONAL INTERVENTION}

Students in an undergraduate psychiatric mental health nursing course participated in this pilot educational initiative that included didactic and clinical learning components over the 15-week semester. The activities were designed to blend components of the flipped classroom and a team-based learning model to maximize classroom instructional time and student performance. Prior to each weekly class meeting, students were assigned chapter readings, supplemental readings, short informational videos, and related handouts. The PowerPoint slides for the upcoming lecture were posted one week before class. Contrary to others that implemented TBL in nursing education, these slides were without narration, though they did contain additional information in the note section of the slides. ${ }^{[1]}$ Instead of instructor-lead pre-class lecture videos, short informational videos from online resources that targeted key concepts were available to the students. Handouts were from relevant sources or instructor developed. All assigned activities were based on the weekly content objectives.

Each class began with an 80-minute discussion of the week's mental health topic. Although similar to a traditional lecture, this discussion time allowed the instructor to explain major concepts and answer student questions without reviewing every detail found in the textbook and other readings. Prior to the implementation of this initiative, all subject material was painstakingly delivered in traditional 3-hour lectures. However, holding student interest for 3-hour was difficult for the instructor. The discussion time in the new model was more energetic and focused on problems the students may encounter in practice, not simple concepts the students could easily grasp. The students came into the classroom with the expectation that they would be required to discuss, critically think and apply the information in learning activity stations. They were also aware that they would be quizzed on the material covered at the end of each class day.

\section{Content experts}

A major change for students from the traditional teaching model, and a key component of the TBL model was content expert group immersion activities. This was designed and developed to give students an opportunity to become more actively engaged in the course content and classroom setting. At the beginning of the semester, students were divided into content expert groups of 8 to 9 members and assigned a topic and classroom time to lead group learning activities. Following the instructor-led discussion, a content expert group set up 4 active learning stations in the classroom. Student groups of 8 to 9 students rotated through each of the studentled learning stations. Because of the large number of students 
and the limited size of the classroom space, one half of the class was dismissed for a break while the other half remained in the classroom and rotated through the stations every 8-10 minutes. When the first half of the class completed the 4 stations, they left the classroom for a break and the other half of the class entered and completed the activities. Each station was led by two students, and the instructor circulated among stations coaching and promoting improved dialogue and engagement. The students, with the guidance of the instructor, designed the brief learning experiences for each station. Each week, at least one station focused on psychiatric medications and another station used NCLEX style questions in a competitive game activity to assess student understanding. The other two stations were more open to creative learning methods. Examples of learning activities included viewing client blogs, videos, medication protocols and various student designed role-playing the important focused content. The following is an example of a four station learning activity focused on depression:

- The first station focused on evidence-based nursing activities related to admitting a patient with suicidal ideation and searching a backpack for contraband.

- In the second station, students role-played therapeutic communication techniques with a suicidal patient and completed a suicide severity rating scale.

- In the third station, antidepressant medications were identified with a matching activity and nursing implications related to adherence were discussed.

- Lastly, in the fourth station, students viewed a blog written by a patient with depression and discussed his personal account of living with a reoccurring, chronic mental health disorder.

A synthesis worksheet was prepared by the assigned content expert group and posted online for review several days before the class. This handout described each of the learning stations objectives and activities and provided additional information the content experts believed relevant for their peers. This worksheet afforded the students the ability to fully engage during the activity without the distraction of taking copious notes. A rubric was developed for grading the activity and focused on the group's creativity, engagement and application of content objectives. Students were also able to rate and provide additional comments about the learning activities by way of an electronic survey distributed after each class.

Evaluating the students' knowledge of the content with quizzes is an important part of this TBL initiative. In the traditional model, a midterm and final exam made up a large portion of the student's grade. Scheduled and impromptu quizzes were mixed in during the semester and only accounted for a small percentage of their grade. This method of testing was dramatically changed with the TBL model, removing the midterm and long exams and replacing these with six, 20-question quizzes scheduled during the semester. Frequent testing encourages students to come to class prepared, read weekly, and avoid some of the memorizing of large amounts of material seen with the previous testing model. ${ }^{[12]}$ All students took a specialty specific nationally normed NCLEX preparation test at the end of the course.

\section{EVALUATION AND RECOMMENDATIONS}

Exam grades, specialty specific nationally normed (NN) test pass rates, and student satisfaction scores for a group of nursing students that received TBL instruction were compared to nursing students in the previous traditional lecture-based format. The team-based learning group consists of two nursing cohorts $(n=153)$ in consecutive semesters (spring \& summer 2016) completing the psychiatric mental health nursing course during their 2 nd semester of an accelerated program. The traditional group also consist of two cohorts $(n=138)$ that completed the same psychiatric mental health nursing course in earlier semesters (summer 2014 \& spring 2015). The cohort of students in the summer of 2015 are not included in this evaluation because the TBL model was only partially implemented for this group and therefore they do not fit into either group. Since this was a curriculum change, all students in the psychiatric mental health nursing course for the indicated years were included in this convenient sample and only standard institutional measurements were collected as part of this evaluation.

The examination schedule was different for each group, but the questions were similar for the traditional students and the TBL group. The independent-samples $t$-test was used to compare the mean exam grades of the TBL group and the traditional group and found a significant difference $(t(6.09)$ $=294, p<.001)$. The mean exam grades for the TBL group were significantly higher by 2.4 percentage points $(\mathrm{sd}=3.64)$ over the traditional group.

Students taking the specialty specific nationally normed NCLEX preparation test were classified as "not passing" if they scored below a level 2 on the predictor exam taken at the end of the semester. This indicated that these students may do poorly on this subject matter on the NCLEX and would benefit from remediation. The exact scores for this exam were not tracked, only pass/fail rates. In the traditional group, $90.6 \%$ of the students passed the predictor exam. The TBL group improved this mark with a $94.2 \%$ pass rate.

At the end of the semester, students completed an anonymous 
survey to rate their satisfaction and collect comments about the course. The ratings are from 1 to 5 with 5 being the highest or best score possible. The university's goal for courses is 4.00 or higher. The psychiatric mental health course had enjoyed high ratings in the past with the traditional group receiving a 4.54 mean satisfaction score. The implementation of the TBL initiative continued these high scores, even improving them to a 4.73 mean satisfaction rating.

Students who participated in this TBL learning activity were excited and engaged in the classroom. Student outcomes were positive, as reflected by improved quiz grades. Positive student feedback was also reported in the course evaluations. Comments included:

- "I looked forward to coming to this class and loved moving through the activities."

- "I felt like I began to really understand the complexity of mental health issues."

- "Interacting with my peers and participating in the learning activities reduced my anxiety about interacting with patients diagnosed with mental health disorders."

Faculty reported feeling less pressure to include all of the important content in a traditional 3 -hour lecture format. Fac- ulty also valued facilitating dialogue with the assigned student content expert groups about how to creatively develop learning activities that would engage peers and meet content objectives. The role of coach or guide replaced the outdated faculty role of "expert", and moved the responsibility of learning to the student. Combining the flipped classroom model with a team-based learning model improved engagement, enthusiasm, and interest in psychiatric mental health nursing as a specialty.

Students in higher education today have at their fingertips an abundance of information that must be filtered, synthesized, and quickly applied. Faculty's new place in student education is to guide them through this process. In order to maximize the time that is spent with students in a college classroom, faculty may find that implementing a team-based active learning model in a flipped classroom is an effective means of transferring the responsibility for learning to the student. By taking ownership of their education, students are more invested in the outcome and better prepared for professional collaboration.

\section{CONFlicts OF InTEREST Disclosure}

The authors declare that there is no conflict of interest.

\section{REFERENCES}

[1] Szpak JL, Kameg KM. Simulation decreases nursing student anxiety prior to communication with mentally ill patients. Clinical Simulation in Nursing. 2013; 9(1): e13-e9.

[2] Happell B, Gaskin CJ. The attitudes of undergraduate nursing students towards mental health nursing: A systematic review. Journal of Clinical Nursing. 2012; 22: 14858. https://doi.org/10.1111/j.1467-9280.2006.01693.x https://doi.org/10.1111/jocn. 12022

[3] Lehr ST, Kaplan B. A mental health simulation experience for baccalaureate student nurses. Clinical Simulation in Nursing. 2013; 9(10): e425-e31. https : //doi.org/10.1016/j.ecns. 2012.12 .003

[4] Benner P, Sutphen M, Leonard V, et al. Educating nurses: A call for radical transformation. San Francisco, CA: Jossey-Bass; 2010.

[5] National Academy of Science. The future of nursing focus on education. In: Medicine Io, editor. 2010.

[6] American Association of Colleges of Nursing. The essentials of baccalaureate education for professional nursing practice. 2008 Available from: http://www . aacn.nche.edu/publications/o rder-form/baccalaureate-essential
[7] Bergmann J, Sams A. Flipping for mastery. Educational Leadership. 2014; 71(4): 24-9.

[8] Harmon RB, Hills RL. Transforming psychiatric mental health nursing education with team based learning. Arch Psychiatr Nurs. 2015; 29(6): 413-8. https ://doi.org/10.1016/j . apnu.2015.06.0 14

[9] Towle A, Kaplan B. Teaching the milennial nursing student: Using the "flipped classroom" model. Nursing and Health. 2014; 2(6): 107-14.

[10] Clark MC, Nguyen HT, Bray C, et al. Team-based learning in an undergraduate nursing course. Journal of Nursing Education. 2008; 47(3): 111-7. PMid:18380264 https ://doi.org/10.3928/0148 4834-20080301-02

[11] Della Ratta CB. Flipping the classroom with team-based learning in undergraduate nursing education. Nurse Educ. 2015; 40(2): 71-4. https://doi.org/10.1097/NNE.0000000000000112

[12] Roediger HL, Karpicke JD. Test-enhanced learning: Taking memory tests improves long-term retention. Psychol Sci. 2006; 17(3): 249-55. https ://doi.org/10.1111/j.1467-9280.2006.01693.x 